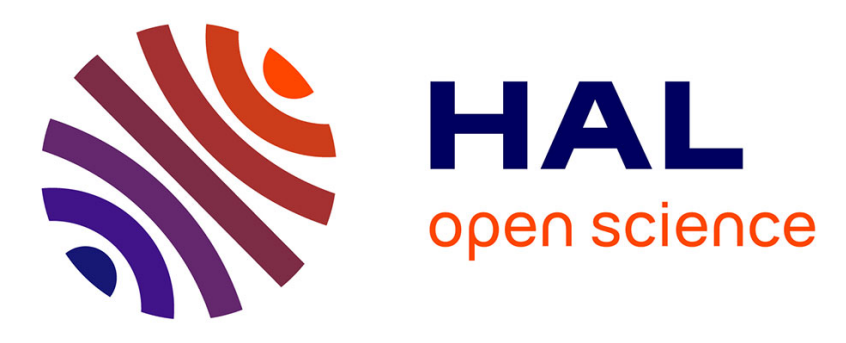

\title{
Effects of Strain Hardening and Fine Structure on Strength and Toughness of Tempered Martensite in Carbon Steels
}

\author{
G. Krauss, D. Matlock
}

\section{- To cite this version:}

G. Krauss, D. Matlock. Effects of Strain Hardening and Fine Structure on Strength and Toughness of Tempered Martensite in Carbon Steels. Journal de Physique IV Proceedings, 1995, 05 (C8), pp.C851-C8-60. 10.1051/jp4:1995806 . jpa-00254054

\section{HAL Id: jpa-00254054 https://hal.science/jpa-00254054}

Submitted on 1 Jan 1995

HAL is a multi-disciplinary open access archive for the deposit and dissemination of scientific research documents, whether they are published or not. The documents may come from teaching and research institutions in France or abroad, or from public or private research centers.
L'archive ouverte pluridisciplinaire HAL, est destinée au dépôt et à la diffusion de documents scientifiques de niveau recherche, publiés ou non, émanant des établissements d'enseignement et de recherche français ou étrangers, des laboratoires publics ou privés. 


\title{
Effects of Strain Hardening and Fine Structure on Strength and Toughness of Tempered Martensite in Carbon Steels
}

\author{
G. Krauss and D.K. Matlock
}

Advanced Steel Processing and Products Research Center, Colorado School of Mines, Golden, Colorado 80401, U.S.A.

\begin{abstract}
A series of medium-carbon low alloy steels was quenched to martensite and tempered at $150 \mathrm{C}$. This low-temperature-tempered (LTT) martensite was subjected to uniaxial tensile and impact testing. Yield and ultimate tensile strength and uniform elongation increased, and post uniform and total elongation and fracture toughness decreased, with increasing carbon concentration. The carbon dependence of the mechanical properties is attributed to the dislocation/transition carbide substructure of the LTT martensite. As carbon content increases, the density of the transition carbide arrays increases, and the rate of strain hardening increases, resulting in the noted property changes. The strain hardening mechanisms and questions remaining about the evolution and characterization of the transition carbide structures are discussed.
\end{abstract}

\section{INTRODUCTION}

Martensite is the major microstructural component of carbon steels used for structural applications which require ultrahigh strength, excellent fatigue resistance, and high wear resistance. In order to accomplish martensitic transformation in commercial sections, nominal amounts, on the order of a few mass percent, of substitutional alloying elements such as $\mathrm{Mn}, \mathrm{Ni}, \mathrm{Cr}$, and $\mathrm{Mo}$ are added to provide hardenability [1], and therefore the commercial hardenable steels are in fact low-alloy steels. However, it is carbon content which largely determines the hardness and strength of lowalloy carbon steels, and Winchell and Cohen [2], and others [3] have related carbon-dependent strengthening of as-quenched $\mathrm{Fe}-\mathrm{Ni}-\mathrm{C}$ martensites to iron atom displacements caused by carbon atoms trapped in octahedral sites of the body-centered-tetragonal crystal structure.

As-quenched martensitic microstructures in commercial sections have unacceptable residual stresses and toughness. Therefore, almost all hardened components are tempered. The higher the tempering temperature, the lower the hardness, and if various types of temper embrittlement are avoided, the higher the toughness of the component. In order to preserve as much of the martensitic strength as possible, as shown in Fig. 1 [4], martensitic steels for applications which require the highest strengths are tempered between 150 and $200 \mathrm{C}$. This range of tempering temperatures is below that which induces tempered martensite embrittlement, and in the balance of this paper the microstructures produced by tempering in this range will be referred to as lowtemperature-tempered (LTT) martensites.

In LTT martensite, supersaturation of carbon in the octahedral interstitial sites of martensite is relieved by precipitation of transition carbides. These transition carbides have been identified as 
epsilon carbides with a hexagonal crystal structure [5] or eta carbides with an orthorhombic crystal structure [6]. The two structures are similar, and electron diffraction patterns from the transition carbides can be readily indexed according to either structure [7]. Regardless of the exact identification of the transition carbides, very fine transition carbide particles in LTT martensite appear to control the strain hardening which results in the very high carbon-dependent strengths of carbon steels [8-11]. The purpose of this paper is to describe this carbon-dependent strain hardening and the associated mechanical properties and fracture behavior in a series of low-alloy, medium-carbon, LTT martensitic steels.

\section{EXPERIMENTAL PROCEDURE}

A series of low-alloy steels, differing only in carbon content, was vacuum melted and hot rolled to plate for this investigation. The steels were based on SAE 43xx compositions and all contained, in mass pet, $0.70 \mathrm{Mn}, 0.26 \mathrm{Si}, 0.81 \mathrm{Cr}, 1.80 \mathrm{Ni}$, and $0.25 \mathrm{Mo}$. The designations of the steels and their carbon contents were $4320(0.21 \mathrm{C}), 4330(0.31 \mathrm{C}), 4340(0.40 \mathrm{C}), 4350(0.50), 4360(0.63 \mathrm{C})$, $4370(0.71 \mathrm{C})$, and $4385(0.84 \mathrm{C})$. Some of the observations are supplemented with results from $41 \mathrm{xx}$ steels which contain nominally 1.0 pct $\mathrm{Cr}$ and 0.20 pct Mo [8-10].

All specimens were austenitized at $936 \mathrm{C}$ for one hour, oil quenched, and tempered at $150 \mathrm{C}$. Standard tensile testing of specimens, with cylindrical gage sections $6.25 \mathrm{~mm}$ in diameter, and standard Charpy V-notch (CVN) impact testing were performed. The tensile and CVN samples were oriented parallel to the rolling direction. Microstructures were examined by light microscopy and fracture surfaces were examined by scanning electron microscopy (SEM).

\subsection{RESULTS}

\subsection{Mechanical Behavior}

Figure 2 shows a family of engineering stress-strain curves for several of the LTT martensitic $43 \mathrm{xx}$ steels. There are systematic differences in strength and ductility as a function of steel carbon content. Yield and ultimate tensile strengths increase with increasing carbon content. Uniform elongation increases slightly, while post uniform and total elongations decrease significantly with increasing steel carbon content. This carbon-dependent mechanical behavior of the $43 \times x$ LTT martensitic steels reproduces that of $41 \mathrm{xx}$ steels evaluated earlier [8].

Table 1 lists the mechanical properties and hardness of the various $43 \times x$ steels, and Figures 3 and 4 plot, respectively, strength and ductility parameters as a function of carbon content for the $41 \mathrm{xx}$ and $43 \times x$ sets of steels. In the carbon range between 0.2 pct $C$ and $0.5 C$, the ultimate tensile strength (UTS) is essentially a linear function of steel carbon content, and may be represented by the following equation:

$$
\operatorname{UTS}(\mathrm{MPa})=710+3,560[\text { pct C] }
$$

The yield strength of the LTT martensites, however, is not a linear function of carbon content, and parallels the carbon dependence of hardness. This behavior may reflect the increasing influence of retained austenite on yielding behavior, since retained austenite in hardened steels increases with increasing carbon content and is stable in the LTT range [12].

The fracture of all the specimens whose stress-strain curves are shown in Figure 2 was ductile. Macroscopically, the specimens developed necking and cup-cone fractures characterized by flat central fracture surfaces and circumferential shear zones. Microscopically, the fracture surfaces consisted of dimples produced by microvoid nucleation, growth and coalescence. The microvoids 
TABLE 1 - Mechanical Properties of 43XX Steels Tempered at $150^{\circ} \mathrm{C}$

\begin{tabular}{||c|c|c|c|c|c|c||}
\hline \hline Alloy & $\begin{array}{c}\text { Yield } \\
\text { Strength } \\
\text { MPa } \\
(\mathrm{ksi})\end{array}$ & $\begin{array}{c}\text { UTS } \\
\text { MPA } \\
(\mathrm{ksi})\end{array}$ & $\begin{array}{c}\text { Hardness } \\
\mathrm{Rc}\end{array}$ & $\begin{array}{c}\text { Uniform } \\
\text { Elongation } \\
(\%)\end{array}$ & $\begin{array}{c}\text { Total } \\
\text { Elongation } \\
(\%)\end{array}$ & $\begin{array}{c}\text { Reduction } \\
\text { of Area } \\
(\%)\end{array}$ \\
\hline 4320 & $\begin{array}{c}1170 \\
(170)\end{array}$ & $\begin{array}{c}1520 \\
(220)\end{array}$ & 44.5 & 4.95 & 16.7 & 60.5 \\
\hline 4330 & $\begin{array}{c}1170 \\
(170)\end{array}$ & $\begin{array}{c}1520 \\
(220)\end{array}$ & 51.1 & 4.91 & 14.8 & 51.6 \\
\hline 4340 & $\begin{array}{c}1590 \\
(230)\end{array}$ & $\begin{array}{c}2210 \\
(320)\end{array}$ & 55.7 & 6.23 & 14.0 & 44.3 \\
\hline 4350 & 1650 & $\begin{array}{c}2410 \\
(350)\end{array}$ & 59.3 & 5.88 & 8.6 & 20.1 \\
\hline 4360 & $\mathrm{X}$ & $\mathrm{X}$ & 61.5 & $\mathrm{X}$ & $\mathrm{X}$ & $\mathrm{X}$ \\
\hline 4370 & $\mathrm{X}$ & $\mathrm{X}$ & 61.9 & $\mathrm{X}$ & $\mathrm{X}$ & $\mathrm{X}$ \\
\hline 4385 & $\mathrm{X}$ & $\mathrm{X}$ & 62.2 & $\mathrm{X}$ & $\mathrm{X}$ & $\mathrm{X}$ \\
\hline
\end{tabular}

nucleated around inclusions, which were in relatively low concentration in the vacuum melted steels, and around relatively fine carbides which have been shown to be retained during austenitizing prior to quenching [9-11]

It was impossible to obtain valid tensile test results for any of the hardened steels which contained more than 0.5 pct $\mathrm{C}$ as the samples failed prior to neck formation. These steels failed by brittle intergranular fracture which has been related to phosphorus segregation and cementite formation on austenite grain boundaries during quenching. This mechanism of embrittlement is similar to a form of tempered martensite embrittlement [13], but occurs on quenching if critical levels of carbon, on the order of 0.6 pct are present in the austenite $[11,14,15]$. In order to differentiate this embrittlement from tempered martensite embrittlement, it has been termed quench embrittlement.

\subsection{Characterization of Strain Hardening}

As will be discussed, a major cause of the carbon-dependence of the mechanical properties of LTT martensitic steels is the effect of fine structure on strain hardening during deformation. Therefore the strain hardening of the steels was characterized as a function of strain by two approaches. Figure 5 shows a Jaoul-Crussard analysis, which plots the log of the strain hardening rate as a function of the log of the true plastic strain [16,17]. At all levels of plastic strain, the strain hardening increases directly with carbon content of the LTT martensite. The overlap of the 4340 and 4350 curves may be due to the sensitivity of the higher carbon steel to premature fracture because of quench embrittlement. Two of the three 4350 specimens failed before plastic instability developed.

Figure 6 shows a plot of the incremental strain hardening exponent, as a function of plastic strain for four of the LTT martensitic steels. The incremental strain hardening exponent, $n_{i}$ is defined as: 


$$
\mathrm{n}_{\mathrm{i}}=\mathrm{d} \sigma / \mathrm{d} \epsilon\left(\epsilon_{\mathrm{p}} / \sigma\right)
$$

where $\mathrm{d} \sigma / \mathrm{d} \epsilon$ is the true strain hardening rate, $\epsilon_{\mathrm{p}}$ is the true plastic strain and $\sigma$ is the true stress.

This measure of strain hardening also shows, at almost all strains, that the strain hardening rate increases directly with steel carbon content.

The increase in strain hardening rate with carbon content correlates with the corresponding increase in uniform strain. This increase in uniform strain directly reflects the effect of strain hardening rate on instability described by:

$$
\frac{d o}{d e}=a
$$

where $\mathrm{d} \sigma / \mathrm{d} \epsilon$ is the true strain hardening rate, and $\sigma$ is the true stress. In equation [3] $\mathrm{d} \sigma / \mathrm{d} \epsilon$ is a function of carbon content and the true stress at instability, $\sigma_{\mathrm{i}}$, can be viewed [18] as the sum of the yield stress, $\sigma_{y}$, and required increase in stress due to strain hardening, $\Delta \sigma$, both of which depend on carbon content, i.e.:

$$
\frac{d \sigma}{d \varepsilon}(c)=\sigma_{y}(c)+\Delta \sigma\left(\frac{d \sigma}{d \varepsilon}, c\right)
$$

In this study, the carbon dependence of $\sigma_{\mathrm{y}}$ is low with respect to the carbon dependence of strain hardening, and thus, an increase in carbon is manifested by an increase in $\Delta \sigma$ through higher values of $\epsilon_{\mathrm{u}}$.

\subsection{Impact Toughness}

Figure 7 shows curves of Charpy V-notch energy absorbed as a function of temperature for all of the LTT martensitic steels. There is a strong dependence of the impact toughness on steel carbon content. For the medium-carbon steels which sustain plastic deformation, impact energy absorbed drops sharply with increasing carbon concentration at all testing temperatures. For the steels containing $0.6 \mathrm{pct}$ carbon or more, the impact toughness is very low, consistent with the sensitivity of these steels to intergranular quench embrittlement.

\section{DISCUSSION}

\subsection{Fine Structure of LTT Martensite and Strain Hardening}

The above results show that a critical factor in the carbon-dependent deformation and fracture of LTT martensite is strain hardening. The higher strain hardening rates of higher carbon microstructures create higher dynamic flow stresses and eventually result in increased uniform elongation and higher ultimate tensile stresses compared to lower carbon microstructures. Since the stresses at tensile instability are already quite high, little necking or post uniform elongation are required to generate the triaxial stresses for ductile fracture in high-carbon LTT martensitic microstructures [9-11]. The reduced requirement for large amounts of non-uniform deformation to generate triaxial stresses for unstable ductile fracture at the root of CVN specimens also correlates with the sharply reduced upper shelf energies in the high-carbon LTT martensites, as shown in Figure 7. 
In LTT martensitic microstructures, the fine structure which controls dynamic dislocation interactions during straining consists of transition carbides and the associated dislocation substructure. Figure 8 shows a dark-field transmission electron micrograph, taken with a diffracted beam from the transition carbides, which shows the transition carbide arrays in a large martensite crystal in a LTT martensitic 4130 steel. No transmission microscopy was performed on the $43 x x$ steels, but the transition carbide arrays are believed to be similar based on the accumulating observations of the transition carbide arrays in many LTT carbon steels [19].

The characteristic signature of transition carbide morphologies which form in the first stage of tempering of martensite in carbon steels is clearly shown in Figure 8, namely linear arrays of very fine particles, 2 to $4 \mathrm{~nm}$ in size. Some monolithic particles, perhaps theta carbide, formed during autotempering of the martensite, are also visible in Figure 8 . The very fine transition carbides are resolvable only in dark-field TEM micrographs. In bright-field TEM micrographs the linear arrays of carbides are completely masked by bands of dark contrast the length of the linear clusters of particles. This contrast may be a result of coherency strains generated by the precipitation of the clusters of transition carbides.

Another element of the fine structure of LTT martensite is the dislocation substructure, but in medium-carbon steels the dislocation substructure to date has not yet been clearly resolved. The dislocation distribution would be a result of the lattice invariant deformation associated with the martensitic transformation, and the modification of the martensitic fine structure by the lattice changes, both of the parent austenite and the transition carbide precipitates, associated with the first stage of tempering. In low carbon steels, the martensite dislocation density has been shown to increase with increasing carbon content $[20,21]$, but in higher carbon steels the dislocation density may be too high for resolution.

Kuhlman-Wilsdorf developed a theory of work hardening which proposes that strain hardening is related to the stresses required to generate new glide dislocations from the longest unrestrained segments in a dislocation substructure [22]. The flow stress, $\tau$, at a given plastic strain is given by:

$$
\tau=\tau_{\mathrm{o}}+\text { const. } \mathrm{Gb} / \overline{\mathbf{I}}
$$

where $\tau_{0}$ is the friction stress, $G$ is the shear modulus, $b$ is the Burgers vector, and $\bar{l}$ is the average momentary link or active dislocation length. The link length is continually reduced by dislocation substructure formation during straining and, therefore, flow stress increases with increasing plastic strain.

With increasing carbon content, the density of the transition carbide clusters has been shown to increase [8,9]. Thus according to Kuhlmann-Wilsdorf [22], shorter active dislocation link lengths would be expected in higher carbon LTT steels, explaining the higher strain hardening rates of those microstructures. The increasing flow stresses during uniaxial tensile testing indicate a continual refinement in the substructure due to the dynamic interactions of the active dislocations with the dislocation/transition carbide arrays. Eventually the substructure must approach a stable configuration, as reflected by decreasing strain hardening, as strains approach those associated with necking instability.

\subsection{Remaining Questions}

Within the above framework which links the dislocation/transition carbide substructure to the strain hardening and mechanical properties of medium-carbon LTT martensitic steels, there are a number of fundamental questions that remain to be answered. 
First, the crystal structure of the transition carbide. As noted in the Introduction, the transition carbide has been identified as epsilon-carbide with a hexagonal structure or eta-carbide with an orthorhombic crystal structure. Critical identifying features of the eta-carbide are very low intensity superlattice diffraction spots associated with the sublattice of carbon atoms as proposed by Hirotsu and Nagakura [6]. Unfortunately, the locations of these spots in electron diffraction patterns coincide directly with oxide diffraction spots which are artifacts associated with electropolishing of thin steel foils for transmission electron microscopy [23]. Perhaps this controversy could be resolved by the use of thinning techniques, such as ion milling, which would minimize or eliminate oxidation of iron foils.

Other questions remain about the evolution of the morphology and distribution of the transition carbides. Several aging reactions prior to the development of the transition carbides have been identified and subjected to extensive crystallographic characterization [23-25]. These aging reactions consist of various forms of carbon atom clustering as identified by diffuse spikes or satellite spots around electron diffraction spots. These clustered regions must eventually provide the carbon for the transition carbides, and it would be interesting to identify the mechanism of this process. The degree of coherency of the transition carbides, and dislocation substructure evolution from that of as-quenched martensite would also merit investigation.

Finally, the nature of the dynamic dislocation interactions with the substructure of the LTT martensite during deformation would be of interest. If the interactions are controlled by the very fine, closely spaced, individual transition carbides, particle shearing is a possible mechanism [26]. This mechanism results in strain localization and may limit ductility. On the other hand, if the interactions are controlled by the linear clusters of transition carbides and the spacing of these carbide clusters, then dislocation cross slip, intersection, and multiplication around the clusters could produce the substructure and continually decreasing dislocation link lengths which contribute to the strain hardening of the LTT martensites. The ability of medium-carbon LTT martensitic steels to sustain plastic deformation and eventually fracture by ductile mechanisms provides evidence for the latter type of dislocation dynamics.

\section{SUMMARY}

This investigation relates the martensitic fine structure of a series of $43 \times x$ LTTmartensitic steels to deformation behavior and mechanical properties. In particular, the increasing density of clusters of fine transition carbides with increasing carbon content correlates with increasing strain hardening rates which raise flow stresses, ultimate tensile stresses and uniform elongation. In higher carbon steels, the higher stresses attained by strain hardening during uniform elongation reduce the amount of necking, and therefore post-uniform and total elongation, required to achieve ductile fracture at second phase particles in the strain hardened LTT martensitic matrix. More detailed knowledge of the transition carbide/dislocation substructure, and its dynamic interactions with dislocation movement during plastic straining, would be desirable.

\section{Acknowledgements}

This work was supported by the Advanced Steel Processing and Products Research Center (ASPPRC), an NSF Industry/University Cooperative Research Center at the Colorado School of Mines. We thank the Timken Company for preparation of the vacuum-melted heats of $43 x x$ steels, and James A. Sanders, now with the Timken Company, for the mechanical testing of the alloys when he was a graduate research assistant in the ASPPRC. 


\section{References}

[1] Krauss, G., Steels: Heat Treatment and Processing Principles (ASM International, Materials Park, Ohio, 1990) pp. 145-178.

[2] Winchell, P.G. and Cohen, M., Trans. ASM, 55 (1962) pp. 347-361

[3] Roberts, M.J. and Owen, W.S., J. Iron and Steel Inst., 206 (1968) pp. 375-384.

[4] Grange, R.A., Hibral, C.R., and Porter, L.F., Metall. Trans. A, 8A (1977) pp. 1775-1785.

[5] Jack, K.H., J. Iron and Steel Inst., 169 (1951) pp. 26-36.

[6] Hirotsu, Y. and Nagakura, S., Acta Metall., 20 (1972) pp. 645-655.

[7] Williamson, D.L., Nakazawa, K., and Krauss, G., Metall. Trans. A, 10A (1979) pp. 1351-1363.

[8] Gu, B., Losz, J.M.B. Losz, and Krauss, G., "Substructure and Flow Strength of LowTemperature Tempered Medium Carbon Martensite" International Conference on Martensitic Transformations, Nara, Japan, 1986, (The Japan Institute of Metals, Tokyo, Japan, 1986) pp. 367374.

[9] Krauss, G., Hart. Tech. Mitt., 46 (1991) pp. 7-15.

[10] Krauss, G., Proceedings, 36th Mechanical Working and Steel Processing Conference, ISSAIME, XXXII (1995) pp. 349-359.

[11] Krauss, G., ISIJ International, 35 No. 4 (1995) pp. 349-359.

[12] Zaccone, M.A. and Krauss, G., Metall. Trans A, 24A (1993) pp. 2263-2277

[13] Materkowski, J.P. and Krauss, G., Metall. Trans A, 10A (1979) pp. 1643-1651.

[14] Hyde, R.S., Ph.D Thesis, Colorado School of Mines, Golden, Colorado (1994).

[15] James, B.A., Ph.D. Thesis, Colorado School of Mines, Golden, Colorado (1994)

[16] Jaoul, B., J. Mech. Phys. Solids, 5 (1957) pp. 95-114.

[17] Crussard, C., Rev. Met. Paris, 10 (1953) pp. 697-710.

[18] Matlock, D.K., Krauss, G., and Zia-Ebrahimi, F., "Strain Hardening of Dual-Phase Steels: An Evaluation of the Importance of Processing History", in Deformation, Processing, and Structure, ed. by G. Krauss (ASM, Metals Park, Ohio, 1984), pp. 47-87.

[19] Lee, H-L. and G.Krauss, "Intralath Carbide Transitions in Martensitic Medium-Carbon Steels Tempered between 200 and 300 C, Gilbert R. Speich Symposium on the Fundamentals of Aging and Tempering in Bainitic and Martensitic Steel Products, Montreal, Quebec, Canada, 25-28 October, 1992, G. Krauss and P. E. Repas Eds. (Iron and Steel Society, Warrendale, Pennsylvania, 1992) pp. 39-43.

[20] Norstrom, L.A., Scandinavian J. of Metallurgy, 5 (1975) pp. 159-165

[21] Kelly, P.M. and Kehoe, M., Supplement to Trans. JIM, 17 (1976) pp. 399-404.

[22] Kuhlmann-Wilsdorf, D., Metall. Trans. A, 16A (1985) pp. 2091-2108

[23] Ohmori, Y. and Tamura, I., Metall. Trans. A, 23A (1992) pp. 2737-2751.

[24] Nagakura, S., Hirotsu, Y., Kusunoki, M., Suzuki, T., and Nakamura, Y., Metall. Trans. A, 14A (1983) pp. 1025-1031.

[25] Taylor, K.A., Chang, L., Olson, G.B., Smith, G.D.W., Cohen, M., and Vander Sande, J.B., Metall. Trans. A, 20A (1989) pp. 2717-2737.

[26] Martin, J.W., "Micromechanisms in Particle Hardened Alloys" (Cambridge University Press, Cambridge, England, 1980), pp. 54-56. 


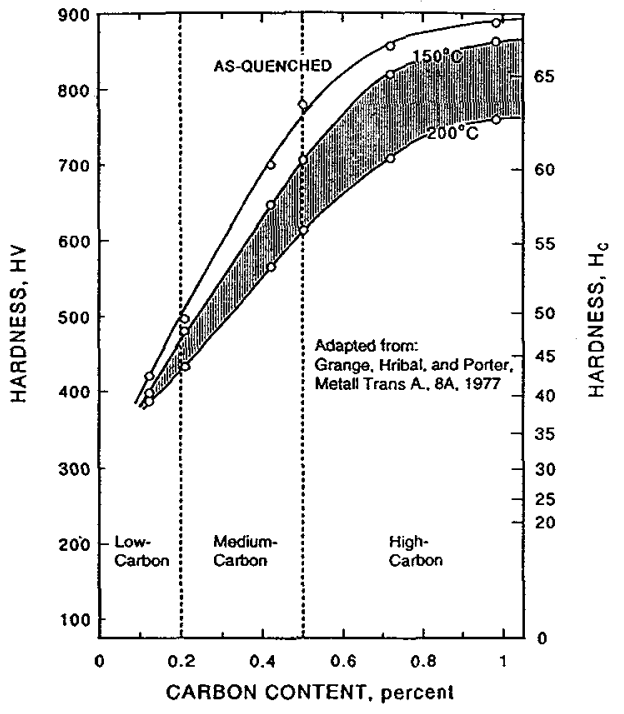

Figure 1: Hardness as a function of steel carbon content for as-quenched and low-temperature-tempered $\left(150\right.$ to $200^{\circ} \mathrm{C}$ ) martensitic microstructures. After Ref. 4.

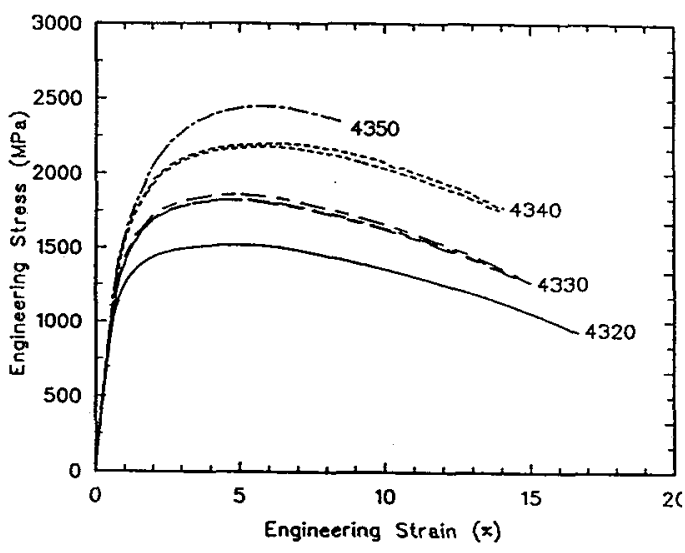

Figure 2: $\quad$ Engineering stress-strain curves for 43xx steels quenched to martensite and tempered at $150^{\circ} \mathrm{C}$

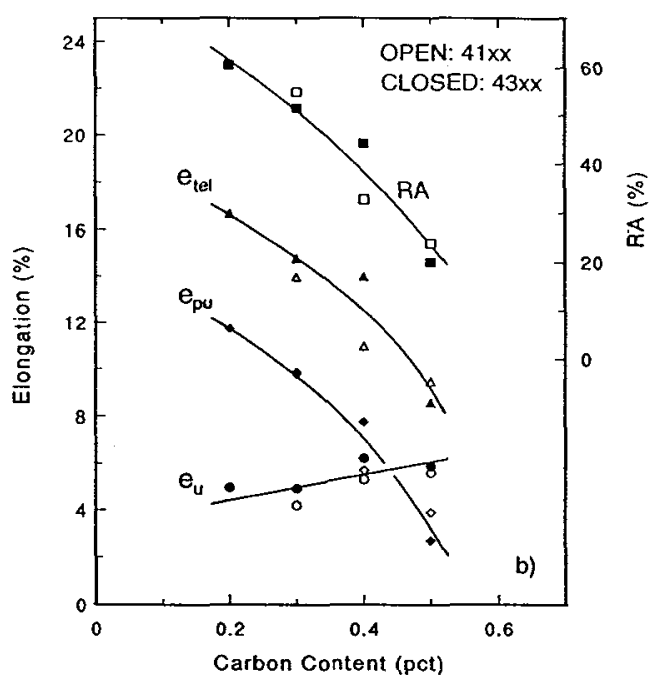

Figure 4: Ductility parameters of LTT martensitic $41 \mathrm{xx}$ and $43 \mathrm{xx}$ steels as a function of carbon content. RA is reduction of area, $\epsilon_{\text {tel }}$ is total elongation, $\epsilon_{\mathrm{pu}}$ is post uniform elongation, and $\epsilon_{\mathrm{u}}$ is uniform elongation. 

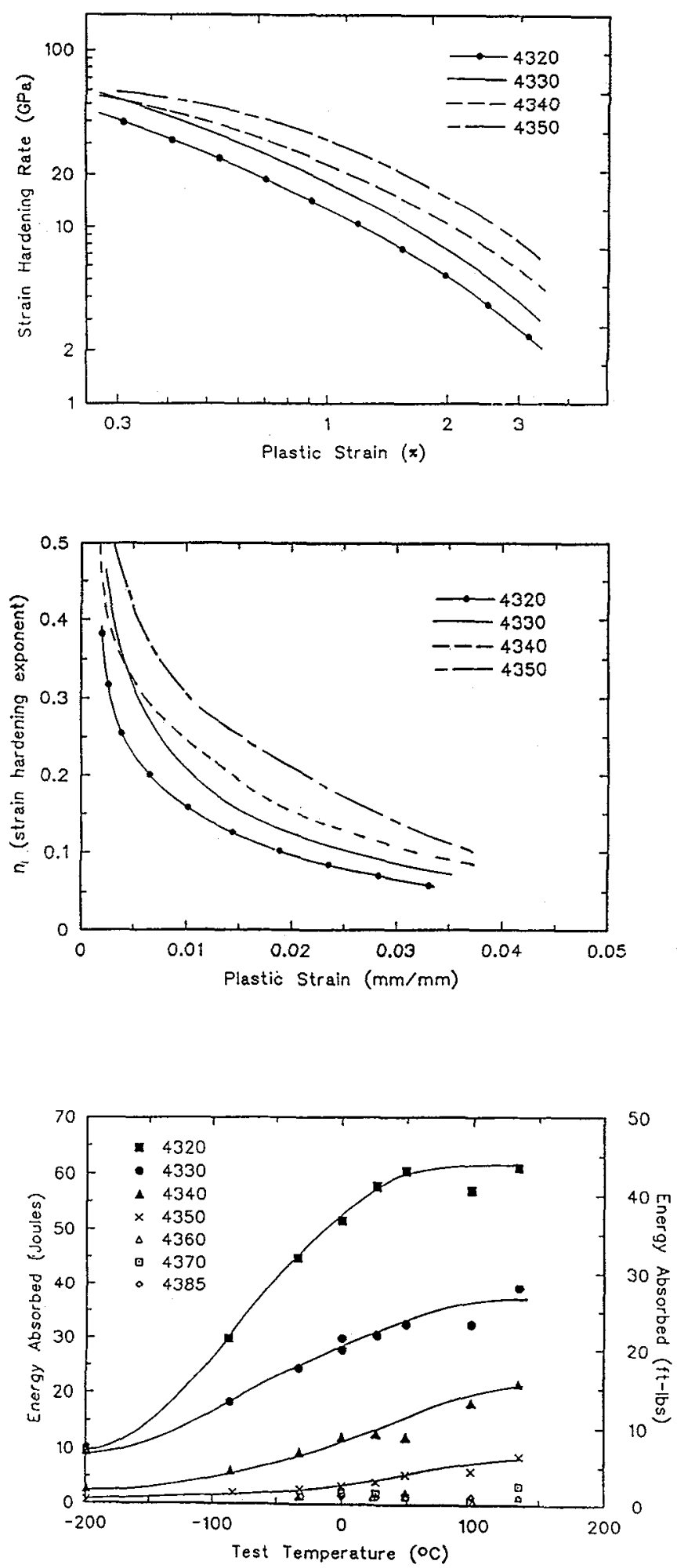

Figure 5: Jaoul-Crussard plot of strain hardening as a function of true plastic strain for LTT martensitic $42 \mathrm{xx}$ steels.

Figure 6: Incremental strain hardening exponent (defined in text) as a function of true plastic strain for LTT martensitic 43xx steels.

Figure 7: $\mathrm{C}$ V N e n e $\mathrm{r}$ g y absorbed as a function of test temperature for LTT martensitic $43 \mathrm{xx}$ steels. 


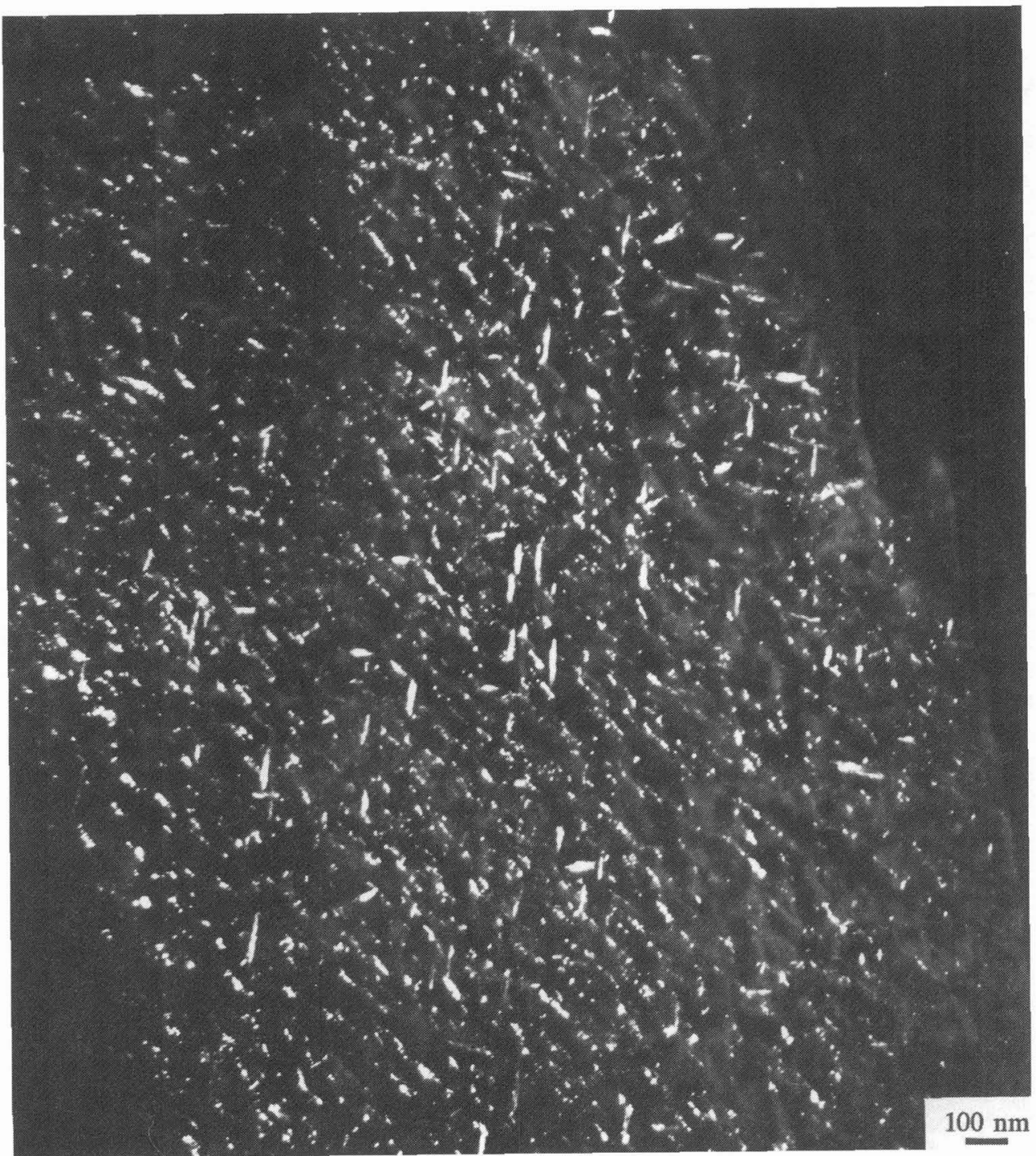

Figure 8: Transition carbide arrays in a martensite lath of 4130 steel tempered at $150^{\circ} \mathrm{C}$. Darkfield TEM micrograph taken with transition carbide diffracted beam. Courtesy of M. Losz. 